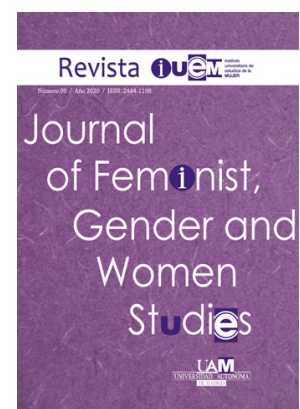

\section{La recepción lésbica de la amazona: el caso Wonder Woman}

\author{
Amazon lesbian reception: the case of Wonder Woman
}

Sara Palermo $0^{1, @ ~}$

${ }^{1}$ Departamento de Filología Clásica. Facultad de Filosofía y Letras. Universidad Autónoma de Madrid. @ Autor/a de correspondencia: Tfno. (+34) 914974533 | Despacho 201-III

\title{
Resumen
}

A lo largo de los siglos, un abanico de identidades modernas se ha apropiado y ha remodelado de manera ininterrumpida varios elementos procedentes del mundo clásico grecorromano, hasta conformar una cadena de recepciones desde un arquetipo original hasta un producto contemporáneo. Así, el modelo de la guerrera amazona ha sido trasmitido hasta mediados del siglo XX, cuando sirvió como referente para el diseño de Wonder Woman, superheroína protagonista del cómic homónimo. A través del marco metodológico ofrecido por los estudios de Recepción Clásica, en este trabajo se lleva a cabo un análisis de las dinámicas de recepción y apropiación del referente amazónico, mediado por el cómic Wonder Woman, por parte del colectivo lésbico. Para ello se indagará primero en los rasgos del arquetipo clásico y su tradición, en relación con la ideología feminista de su creador, William Moulton Marston. El objetivo final es la identificación de los elementos propios del referente clásico y de su reescritura que han permitido la reinterpretación lésbica del mismo, entre los que destacan la agentividad de las amazonas, su ubicación geográfica en una isla y el recurso al disfraz de la superheroína.

Palabras clave: amazonas, Wonder Woman, lesbianismo, Recepción Clásica.

\begin{abstract}
Over the centuries, several elements from Classical Antiquity have been adapted and remodelled to give a voice to modern identities, creating a chain of receptions going from the archetype to the contemporary product. Thus, the warrior woman model encapsulated by the Amazon has been transmitted until 20th century, when it served as a reference for the creation of Wonder Woman, from the homonymous comic. Using Classical Reception theory as a framework, this paper seeks to analyse the dynamics of reception and appropriation of the Amazon by the lesbian collective, through the comic book Wonder Woman. For that purpose, it will delve into the features of the classical archetype and its tradition, in relation to the feminist ideology of its creator, William Moulton Marston. The ultimate goal is the identification of the elements of the classic referent and its rewriting that paved the way to its lesbian reinterpretation, among which Amazons' agency stands out, together with their geographical location on an island and the superhero costume.
\end{abstract}

Keywords: Amazons, Wonder Woman, lesbianism, Classical Reception. 


\section{INTRODUCCIÓN}

«Las lesbianas no son mujeres». Con esta expresión terminaba en 1978 Monique Wittig su intervención titulada «El pensamiento heterosexual», en la Modern Language Association Convention. La justificación de este postulado se encontraba en la idea de Wittig de que "la-mujer' no tiene sentido más que en los sistemas heterosexuales de pensamiento y en los sistemas económicos heterosexuales» (Wittig, 1992: p. 57), sistemas ambos que encuentran en la Antigüedad clásica grecorromana la semilla para su desarrollo y legitimación.

En los años cuarenta del siglo pasado hizo su aparición en escena el cómic Wonder Woman, la Mujer Maravilla ${ }^{1}$, un personaje que desafió el discurso hegemónico masculino bajo diferentes aspectos. La agentividad de esta heroína, sus poderes, su ideología y su sexualidad se oponían firmemente a los roles de género socialmente impuestos a la mujer de la década de los cuarenta. Este personaje fue modelado por su creador, William Moulton Marston (1893-1947), con la intención de educar a un público norteamericano esencialmente masculino, buscando una identificación con el ideal femenino vehiculado por la Mujer Maravilla al margen del género (sobre el objetivo del autor, véase más adelante). Sin embargo, no fueron los varones los únicos receptores del mensaje, sino que este se extendió y fue acogido también por las mujeres; ellas hicieron suya a Wonder Woman, exaltando su valor feminista, además de convertirla con posterioridad, en el caso del colectivo lésbico, en un referente con el que identificarse.

\section{EL PERSONAJE Y SU HISTORIA: DIANA PRINCE, WONDER WOMAN}

El personaje de Wonder Woman hizo su primera aparición en diciembre de 1941 en All Star Comics \#8, serie antológica de cómics de la editorial All-American Publications. Poco después, en enero de 1942, consiguió su primer papel protagonista en el primer número de Sensation Comics (Figura 1), otra serie antológica publicada por DC Comics (editorial en la que había confluido la All-American Publications). La idea original fue del psicólogo estadounidense William Moulton Marston (1893-1947), quien escribió el guion bajo el pseudónimo de Charles Moulton; el primer dibujante de la serie fue Harry G. Peter (1880-1958), responsable de la estética e iconografía del cómic hasta su muerte.

Según la historia original elaborada por Marston, la reina de las amazonas, Hipólita, moldeó a su hija Diana, futura Wonder Woman, a partir de la arcilla, y la diosa Afrodita le concedió la vida atendiendo a las súplicas de su madre; la niña fue criada por las amazonas y creció desarrollando

1 Título por el que se conoce la serie de cómic y la misma heroína en España e Hispanoamérica. Las editoriales, sin embargo, mantienen el título en inglés en sus publicaciones.

2 Los creadores que sucedieron a Marston introdujeron en la historia a Zeus, señor del Olimpo, como responsable de insuflar en la estatuilla de arcilla su soplo vital. La inclusión de este nuevo personaje sirvió tanto para justificar la ascendencia divina de la heroína, como para normativizar el nacimiento del personaje a través de la implicación del elemento masculino en la procreación (el soplo vital como el semen que fecunda). El cambio será muy evidente en la etapa The New 52, cuando la heroína pasará a ser una semidiosa nacida por la unión carnal entre Hipólita y Zeus.

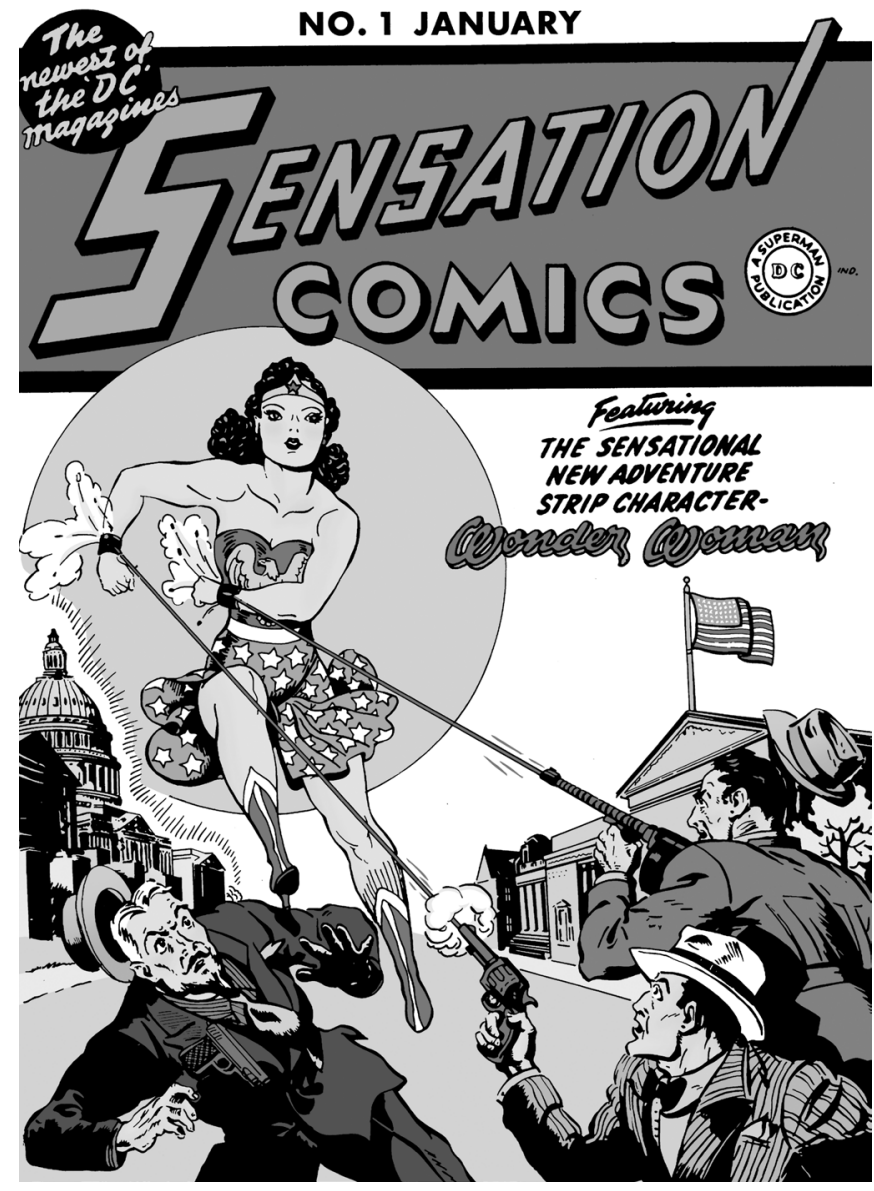

Figura 1. Sensation Comics \#1 - Portada, enero 1942 (TM \& (C) 2020 DC COMICS).

los poderes sobrehumanos que los dioses griegos le habían otorgado. Su objetivo de vida será la lucha contra cualquier forma de injusticia, que se encarna en un largo listado de supervillanos, como el Doctor Poison, el Doctor Psycho, Cheetah o, modelados a partir de la mitología griega, Circe y Ares, sin olvidar la representación de las tropas nazis, ya que el cómic se estrenó durante los primeros años de la Segunda Guerra Mundial.

La princesa Diana vive y crece en Isla Paraíso, conocida también como Temiscira, un lugar habitado exclusivamente por amazonas, al que los hombres tienen vedado el acceso. Sin embargo, para poder llevar a cabo su misión y su lucha contra la injusticia, Diana se ve obligada a menudo a abandonar la isla para vivir en Man's World, el Mundo de los Hombres ${ }^{3}$, donde adopta una identidad civil bajo el nombre de Diana Prince. El guiño directo al referente amazónico es evidente ya en el nombre de la heroína: Diana es el nombre romano de la diosa de la caza, equivalente a la griega Ártemis, a cuyo culto, como se verá, eran devotas las amazonas.

Como otras superheroínas y superhéroes, para ocultar su verdadera identidad, también Wonder Woman lleva un traje, que consiste en una tiara dorada, pantalones cortos azules recubiertos de estrellas y un corsé rojo con un águila dorada. Su iconografía es claramente patriótica, como se aprecia en la clara semejanza de colores y motivos con

3 Así se define en el cómic, en su traducción al español, el Man's World, todo el mundo fuera de Isla Paraíso y dominado por el hombre. 
la simbología del poder estadounidense, tanto en lo que se refiere a la bandera stars and stripes, como al águila. Por otra parte, la representación de Wonder Woman está íntimamente relacionada con la de Columbia (Figura 2), personificación femenina de Estados Unidos (como la francesa Marianne o Italia Turrita del Belpaese), ampliamente aprovechada por las sufragistas en sus marchas en las primeras décadas del siglo XX. Como se explicará más adelante, este parecido fue intencionado, buscado por el creador de Wonder Woman para ofrecer al público la imagen de una sociedad femenina ideal, que vehiculara su percepción personal acerca del papel de la mujer en la sociedad.

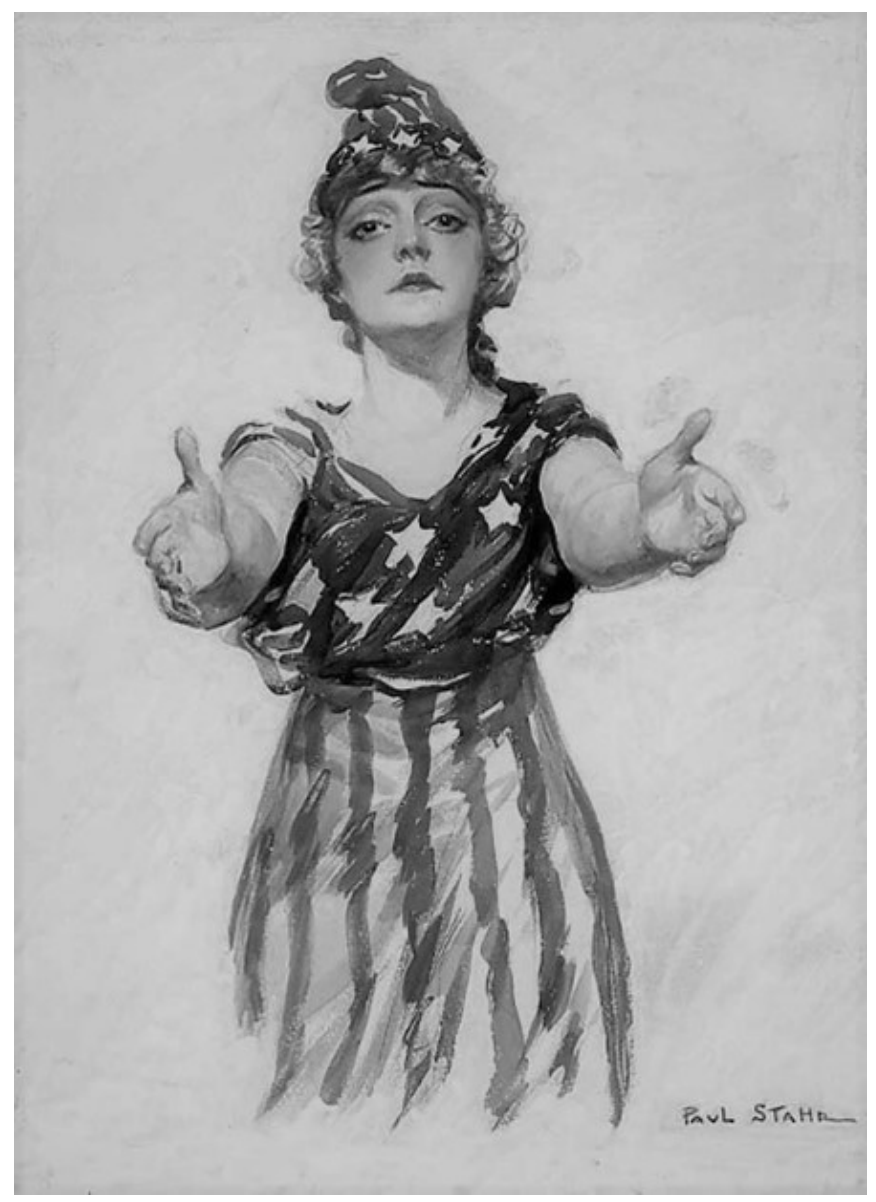

Figura 2. Personificación de Columbia. Be Patriotic, Paul Stahr (1917-1918).

Las armas principales de Wonder Woman son su tiara, símbolo de su rango de princesa y usada como proyectil, los indestructibles brazaletes para parar las balas y el famoso lazo de la verdad, con el cual obliga a sus enemigos a confesar sus crímenes y a someterse a su poder. Las características de estas últimas armas esconden un reflejo, que se desarrollará más adelante, de las ideas de Marston acerca de la sumisión positiva del individuo: tanto los brazaletes como el lazo de la verdad guardan relación con la práctica del bondage 4 y, además, con el detector de mentiras, artilugio que se dice diseñado por el mismo Marston, con la aportación

4 Escribe Lewis (2013: p. 40) «When questioned about her bracelets, Wonder Woman emphasizes that they represent a positive kind of bondage: "our bracelets bind [cursiva en el texto original] our strength to the service of love and beauty" (Marston and Peter 1943/2002: 145)». fundamental de su mujer, Elizabeth Holloway (1893-1993) (Lepore, 2004: p. 48-49).

\section{Las etapas de la historia de Wonder Woman}

En un artículo publicado en 2005, Kelli E. Stanley identificó los principales cambios experimentados por el personaje de Wonder Woman, desde su asociación con Rosie the Riveter, 'Rosie, la remachadora', a lo largo de los años cuarenta, hasta la búsqueda obsesiva de un amor romántico (masculino, se entiende), debido a una acusación de lesbianismo que envolvió al personaje en los años cincuenta. También pasó por un periodo en el que se mantuvo sin poderes durante los años sesenta y setenta, para volver, en los ochenta, a una relación más fiel con la mitología griega y a una representación hipersexualizada en los noventa, adoptando una estética de bad girl. Con la llegada del nuevo siglo, incluso las Naciones Unidas convirtieron a este personaje de ficción en embajadora honorífica de paz de este organismo internacional ${ }^{5}$.

Estas fases tan diferentes en la historia de la evolución del personaje y su iconografía se corresponden con sendos momentos de la historia del formato cómic. Se trata de un hecho común a todas las casas editoriales, debido, entre otros factores, al Zeitgeist o espíritu de la época, la censura o la cultura mainstream. Claramente, a cada uno de estos momentos corresponden diferentes creadores de guion y dibujantes ${ }^{6}$. Se suele distinguir entre la Edad Dorada (Ios cuarenta y hasta poco después de la muerte de Marston en 1947), la Edad de Plata (los cncuenta, después de la acusación de lesbianismo), la Edad de Bronce (los sesenta y los setenta), la Crisis on Infinite Earths y la post-Crisis (los ochenta y los noventa), hasta llegar por fin a la época del The New 52, con el relanzamiento de DC Comics'.

Tal y como suele ocurrir con los productos artísticos de la cultura pop, también el cómic Wonder Woman experimentó un proceso de transmedialidad, esto es, el trasvase de contenidos de un formato a otro. Más allá de todo el merchandising asociado a su personaje, sus aventuras traspasaron los confines de la historieta y fueron representadas en series televisivas y en películas, las más famosas de las cuales son la serie Wonder Woman (ABC, 1975-1979), protagonizada por Lynda Carter, y el filme Wonder Woman (Patty Jenkins, 2017), con Gal Gadot en el papel de la Mujer Maravilla.

\footnotetext{
5 Elegida como embajadora el 21 de octubre de 2016 para apoyar el Objetivo de Desarrollo Sostenible n. 5 (igualdad de género y empoderamiento de las mujeres), su nombramiento fue revocado en diciembre del mismo año, debido a las protestas que subrayaban la inconsistencia de la elección para este cargo de un personaje de ficción extremamente sexualizado y cosificado (United Nations, 2016).

6 Citando solo a algunos, Wonder Woman pasó por las manos de Marston y Peter, seguidos por Robert Kanigher y Mike Sekowsky en la Edad de Plata, de Bronce y la Crisis on Infinite Earths, George Pérez, Phil Jiménez, Greg Rucka, J. Michael Straczynski en la etapa post-Crisis, hasta Brian Azzarello con el dibujo de Cliff Chiang en la época The New 52.

7 Acerca de las diferentes etapas de la historia del cómic, se pueden consultar, entre otros, Masotta (1970), Hatfield (2005) y Duncan et al. (2009).
} 


\section{EL ARQUETIPO CLÁSICO DE WONDER WOMAN: LA AMAZONA}

El referente clásico usado como modelo tanto para la construcción del personaje de Wonder Woman como para el espacio en el que vive, es obviamente el mito de las amazonas. De acuerdo con las fuentes clásicas ${ }^{8}$, la sociedad amazónica era exclusivamente femenina, compuesta por guerreras que vivían y actuaban bajo la protección de Ares, dios de la guerra, y Ártemis, diosa de la caza, los espacios salvajes y la virginidad. Gobernaban su pueblo sin la intervención de ningún hombre y toleraban el contacto con los varones solo en forma de sacrificio ritual anual, para reproducirse y garantizar una descendencia a su estirpe. Según se cuenta en el mito, mataban o devolvían a sus padres a los hijos varones, mientras que criaban a las niñas de manera comunitaria, educándolas en el arte de la guerra desde los primeros años de vida. Por lo general, se creía que su tierra se ubicaba geográficamente en la zona del Cáucaso o bien a orillas del mar Negro, en la actual Turquía, y, más específicamente, en Temiscira, según Apolonio Rodio, Apolodoro y Diodoro Sículo?.

En las narraciones mitológicas, las amazonas se asocian principalmente a tres episodios, todos ellos representativos de su papel en la sociedad, que se percibe como en conflicto con y subordinado al varón. El primero de ellos es el noveno de los doce trabajos de Heracles, que consistía en hacerse con el cinturón sagrado que había sido entregado a la reina de las amazonas, Hipólita, por su padre Ares. El segundo acontecimiento mitológico destacable en el mito amazónico es el rapto de Antíope, hermana de la reina Hipólita (o de la propia Hipólita, según algunas variantes) ${ }^{10}$ por parte de Teseo, héroe ateniense que había acompañado a Heracles en su trabajo; debido a ello, las amazonas atacaron Atenas para rescatarla y fueron derrotadas. El último de los momentos mitológicos que se suele asociar al relato amazónico es el combate, durante la guerra de Troya, entre Aquiles, héroe griego por excelencia, y Pentesilea, otra reina de las amazonas, que combatía en el bando troyano. El héroe le infligió la herida mortal típica ${ }^{11}$ de las amazonas: le atravesó el pecho con la lanza, pero, al verla morir, quedó subyugado por su belleza y se enamoró de ella.

La tendencia principal en la cultura griega era la de representar a las amazonas como "lo otro», un elemento externo a la sociedad griega civilizada, bárbaro y, por lo tanto, peligroso para el orden establecido. En consecuencia, eran consideradas una amenaza para las normas sociales y la civilización, ya que se ubicaban, incluso geográficamente,

\footnotetext{
8 Referencias a las amazonas en fuentes clásicas grecorromanas pueden encontrarse en Ilíada III 189y VI 186; Heródoto IV 110; Eurípides, Heracles 408; Apolonio Rodio, Argonáuticas II 966-1000; Apolodoro, Biblioteca II 5, 9; Diodoro Sículo IV 16 y 28; Higino, Fábulas 30; Virgilio, Eneida I 490; Estrabón, Geografía XI 5, 1-4; Plutarco, Vida de Teseo 26-28; Pausanias I 2, 1 además de 15, 2 y 41, 7; Quinto de Esmirna V 42-47; entre otras.

9 Es posible ampliar la información acerca de la descripción literaria y los hallazgos arqueológicos relacionados con el pueblo de las amazonas en Dowden (1997) y Mayor (2014).

10 Véase Plutarco, Vida de Teseo 26-28.

11 Una constante en la descripción de la muerte de mujeres guerreras es la penetración de su cuerpo ya sea con una flecha, una espada o una lanza, bien en el pecho, bien en la vagina. Sobre el tema, véanse las investigaciones en curso de Annalisa Perrotta (2015: p. 55-57).
}

fuera de la estructura patriarcal de la sociedad; desde la perspectiva antigua, vencerlas era necesario, además de justo. A este respecto puede ser interesante observar que Simone de Beauvoir en su obra El segundo sexo (1949) definía a las mujeres en los mismos términos negativos, como «lo otro», todo lo que no es hombre. Esta asociación de ideas permite identificar la persistencia de la idea de la alteridad femenina como un elemento amenazante para la hegemonía patriarcal. En el mundo antiguo las amazonas son cosificadas, reducidas a objetos que pueden y deben ser destruidos por el dominio masculino, muy lejos de ser consideradas seres humanos (y aún más, seres humanos merecedores de que se le reconocieran algún tipo de derecho), debido tanto al hecho de ser mujeres como a la apropiación de un espacio, la guerra, que se consideraba exclusivo del hombre.

Más allá de algunos hallazgos arqueológicos que pueden ser interpretados como evidencias del fundamento histórico de una sociedad amazónica, lo que se puede deducir de un análisis de las fuentes literarias es que las amazonas fueron «inventadas» por el hombre, para justificar su control sobre las mujeres y sobre cualquier otra identidad no normativa. Huelga recordar que los autores de los textos comentados eran varones pertenecientes, en la mayor parte de los casos, a altos estamentos sociales.

El mito de las amazonas ha sido una constante a lo largo de la tradición cultural occidental. Jaqueline FabreSerris en una ponencia reciente (2019) señalaba que la razón de esta recurrencia radica en el verdadero conflicto encarnado por estas guerreras, eso es, la eterna lucha entre hombres y mujeres. Si en las fuentes clásicas grecorromanas las amazonas eran representadas con el único fin de destruirlas, su suerte no varió mucho entre la Edad Media y la época romántica, puesto que, cuando no se las mataba, los autores las reconducían a la normatividad a través de su enamoramiento por el héroe de turno ${ }^{12}$. Fue tan solo a finales del siglo XIX cuando el antiguo mito amazónico fue recuperado con un nuevo matiz de significado, al ser usado para definir a mujeres rebeldes de la Revolución Francesa, como Théroigne de Méricourt (1762-1817). Conocida como «la amazona escarlata», Théroigne adiestró en la lucha cuerpo a cuerpo a un escuadrón de mujeres humildes, llamadas «phalange d'amazones» (McCausland, 2014: p. 62-63). Así pues, cuando el arquetipo mitológico llega hasta William Marston, ya ha generado una serie de recepciones a las que el creador de Wonder Woman añade su propia versión. El personaje del cómic, de hecho, se contrapone a toda esta tradición y propone la devolución a la amazona mitológica de su agentividad. Este proceso va acompañado por la inclusión en la representación de rasgos propios de los personajes de ficción más populares en su época, los superhéroes, como la fuerza sobrehumana, que subraya la relación existente entre el prototipo superheroico y la mitología clásica ${ }^{13}$. El resultado

\footnotetext{
12 Valgan como ejemplos las obras The Masque of Blackness (1605), de Ben Jonson, y The Sea Voyage (1622), de John Fletcher y Philip Massinger, a las que se deben añadir las crónicas españolas y portuguesas desde el Nuevo Mundo; en época romántica destaca la Pentesilea (1808) de Heinrich von Kleist; véase al respecto McCausland (2014: p. 61-62). Ya en el mundo antiguo, sin embargo, la única alternativa a la muerte para una amazona era el matrimonio, institución civilizadora por excelencia (Dowden, 1997: p. 123).
}

13 Sobre el tema, véase Unceta Gómez (2020). Para un estudio de los cómics desde la perspectiva de la Recepción Clásica, véase también Kovacs y 
es una amalgama de elementos arquetípicos y novedosos, que multiplican los significados de la amazona Wonder Woman y potencian los valores asociados al empoderamiento de la mujer. Siguiendo las tipologías de recepciones descritas por Hardwick (2003: p. 9-10), en la reescritura de la amazona en Wonder Woman nos encontramos con una amalgama entre apropiación, intervención e hibridación (sigo las traducciones de los conceptos al español de Sánchez Pérez, 2019: p. 1718), puesto que la recepción se da en el contexto cultural específico del autor, a través de la reelaboración de la fuente con la intención de generar crítica social y recurriendo a la fusión de materiales procedentes tanto de la cultura clásica como de otros momentos históricos.

\section{Las fuentes de Marston}

El autor de Wonder Woman entró en contacto con el mundo clásico desde su formación escolar, puesto que recibió una educación basada fundamentalmente en los clásicos, algo nada raro en los Estados Unidos a principios del siglo XX. Por otra parte, resulta destacable la aportación de su mujer, Elizabeth Holloway, a sus conocimientos del mundo clásico. Ella también había recibido una educación basada en los clásicos grecolatinos en el prestigioso Mountain Holyhoke College, lugar en el que surgieron también sus ideas feministas. Tal fue la fascinación de Holloway por el mundo griego, que Safo se convirtió pronto en su poetisa favorita ${ }^{14}$, tras la lectura de Sappho: Memoir, Text, Selected Rendering and a Literal Translation (1885), editado y traducido por Henry Thornton Wharton (Lepore, 2014: p. 18).

No se puede, además, hablar de la percepción de Marston del personaje de la mujer guerrera sin hacer referencia a otras obras de su época que resucitaban a la amazona, atribuyéndole nuevos valores. Entre estas obras, cabe señalar Herland (1915), de Charlotte Perkins Gilman y Angel Island (1914), de Inez Haynes Irwin, escrita bajo el pseudónimo de Inez Haynes Gilmore. Las dos obras constituyen ejemplos claros de la manera en la que el mito clásico puede ser reinterpretado para adaptarse a las necesidades de un contexto cultural e histórico específico. En Herland (1915), Charlotte Perkins Gilman imagina una sociedad compuesta exclusivamente por mujeres que viven en África, las cuales habían asesinado a los hombres después de haber sido violadas por ellos; un aspecto muy interesante de esta novela es la idea utópica de un mundo en el que los hombres no son necesarios para la reproducción, puesto que las mujeres pueden procrear por partenogénesis, es decir, una reproducción asexual totalmente femenina, según sugieren las palabras griegas que la componen, $\pi \alpha \rho \theta \varepsilon \dot{v}$ o

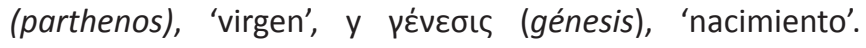
También Angel Island (1914) de Inez Haynes Gilmore se articula alrededor de una recepción distópica del mito de las amazonas, imaginando una isla habitada por mujeres aladas, cuyas extremidades han sido cortadas por los hombres ${ }^{15}$.

\footnotetext{
Marshall (2011 y 2015).
}

14 Según cuenta su hijo, Holloway murió con un ejemplar de los poemas de Safo en la mesilla de noche, ya que no quiso alejarse de sus versos ni en los últimos momentos de su vida (Penrose, 2019: 194).

15 Antecedente de estas obras podría considerarse también la novela New Amazonia. A Foretaste of the Future (1889) de Elizabeth Burgoyne Corbett, en la que se representa una sociedad en la que hombres y mujeres viven
Ambas novelas pudieron proporcionar a Marston una imagen de la amazona que se ajustaba muy bien a sus teorías utópicas sobre un mundo dominado exclusivamente por mujeres, con justicia, orden y amor. De hecho, los dos textos representan sendas descripciones de una sociedad amazónica, compuesta y gobernada exclusivamente por mujeres, ubicada geográficamente en una isla, donde la vida empieza a empeorar debido a la irrupción en ella de los hombres. No resulta difícil imaginar que en estas descripciones pudo residir la semilla de lo que será Temiscira en el cómic Wonder Woman.

\section{WILLIAM MARSTON Y EL FEMINISMO EN WONDER WOMAN}

En una entrevista realizada en marzo de 1945, William Moulton Marston afirmaba: «Frankly, Wonder Woman is psychological propaganda for the new type of woman who, I believe, should rule the world» (Finn, 2014: p. 7). Estas palabras aclaran bastante bien la visión de Marston acerca del papel de la mujer en la sociedad de su época. Abrazando los principios de la primera ola del feminismo ${ }^{16}$, había hecho confluir sus ideales en el personaje de Diana Prince y había representado el "país de las amazonas» como una sociedad feminista perfecta, es decir, utópica. En suma, podríamos afirmar que Marston utilizó el mito de las amazonas para dibujar y justificar el origen de Diana de Temiscira, con la intención de trasmitir sus teorías sobre el matriarcado a un público potencialmente muy amplio.

Es necesario, sin embargo, subrayar que el feminismo, tal y como lo consideraba Marston, tenía como objetivo conseguir el sufragio universal y otros derechos para las mujeres, pero no apuntaba todavía a la deconstrucción de la hegemonía patriarcal o de la jerarquía entre géneros y sus expresiones, ni tampoco aspiraba a la igualdad entre hombres y mujeres, que fueron una característica más bien de la segunda ola del feminismo.

Asimismo, deberíamos tener en cuenta en todo momento que la idea original de Wonder Woman no nació exclusivamente de la creatividad de Marston. Hace poco, uno de sus hijos (Penrose, 2014: p. 194) declaró que su madre, Elizabeth, había tenido un peso relevante en la creación del cómic, como también las otras dos mujeres con las que Marston y Holloway estaban sentimentalmente vinculados, Olive Byrne Richards (1904-1989) y Marjorie Wilkes Huntley (1889-1896). Luego, en su vida personal, lejos de conformarse con los cánones afectivos normativos de la época (y tampoco de los actuales), otorgaban gran importancia a la libre exploración y búsqueda de las posibilidades afectivas y sexuales ${ }^{17}$.

en situación de igualdad, si bien ellos no pueden ejercer cargos públicos. 16 Si bien por fechas la publicación del cómic coincide con el principio de la segunda ola del feminismo, los ideales de Marston están más vinculados con la primera, ya que no presenta todavía el matiz de deconstrucción de la jerarquía patriarcal propio de la segunda y se centra más bien en los derechos de la mujer.

17 Marston, Holloway, Byrne y Wilkes se unieron a una especie de «secta sexual» en Boston, dedicada especialmente al poder sexual femenino (Penrose, 2019: p. 190-191) y que Jill Lepore definió "sexual training camp» (2014: p. 118). En ella fueron iniciados en las prácticas de la sumisión y el bondage. La amplitud de su percepción sobre las relaciones sentimentales y físicas se ve abundantemente reflejada en los contenidos sexualmente 


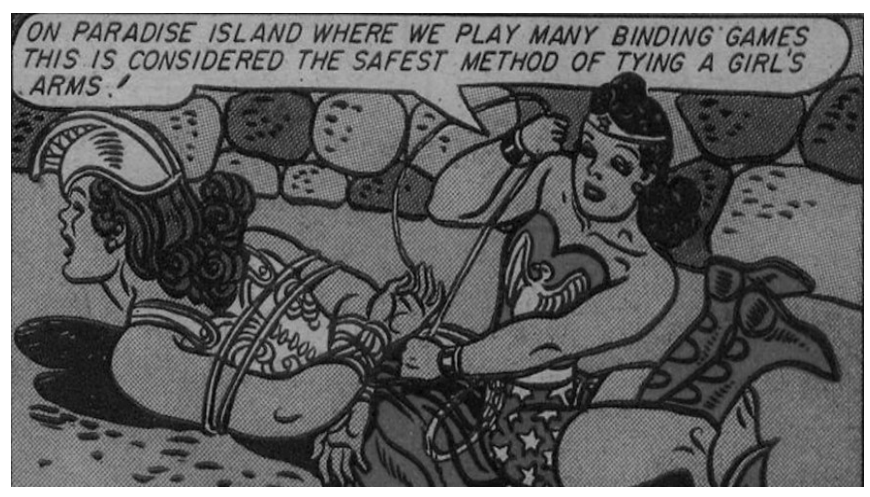

Figura 3. Sensation Comics \#35 - Noviembre 1944 (TM \& (C) 2020 DC COMICS).

Tanto Marston como Holloway, durante sus años en Harvard y Mountain Holyhoke respectivamente, entraron en contacto con ideales feministas, como el voto para las mujeres, su derecho al trabajo y el rechazo de la idea de que las mujeres no tenían derecho a un deseo sexual propio, derivada de una clara distinción entre sexo y reproducción, además de la necesidad de las mujeres de gestionar el control de natalidad. También Olive Byrne, su compañera, estaba íntimamente relacionada con el movimiento feminista: era la sobrina de Margaret Sanger (1879-1966), una famosa sufragista y activista para el control de la natalidad, que en 1914 fundó el periódico The Woman Rebel, con una vida de tan solo ocho números, pero que influyó profundamente en la agenda feminista de principios del siglo $X^{18}$.

Por otro lado, hasta aproximadamente los años 19101913, cuando la palabra "feminismo» empezó a ser más popular debido a los logros conseguidos por los movimientos sufragistas, el término "amazona» era el preferido a la hora de identificar a las mujeres que mostraban cierta rebeldía frente al control que les era impuesto, por ejemplo, cuando decidían abandonar su hogar para tener acceso a una mejor educación. El uso de esta palabra constituye la base para las teorías desarrolladas por el antropólogo alemán Johann Jakob Bachofen a finales del siglo XIX, quien conjeturó la existencia de un matriarcado prehistórico, una sociedad protocomunista compuesta por mujeres, nacida tras los repetidos abusos y violaciones que estas habían sufrido por parte de los hombres ${ }^{19}$. En su teoría, Bachofen imaginaba también la promiscuidad como un elemento importante de esta sociedad, aspecto que fue considerado negativo y por lo tanto eliminado por algunas de las feministas de la primera ola, que decidieron recurrir al arquetipo clásico de la amazona para justificar el feminismo amazónico, que fundamentaba la igualdad entre hombres y mujeres en la igualdad física ${ }^{20}$.

La plasmación de las ideas feministas de Marston y sus compañeras en el personaje de Wonder Woman se hacen evidentes, por ejemplo, en la necesidad imperante de la heroína de perseguir la justicia en todo momento, como

explícitos del cómic que incluyen también referencias a prácticas kinky (Figura 3).

18 A Sanger está dedicado el cómic La mujer rebelde: la historia de Margaret Sanger (La Cúpula, 2013), de Peter Bagge.

19 Véanse, entre otros, Davies (2009) y Santini (2009).

20 De esta constatación deriva la importancia otorgada a la eficiencia física, a la corporeidad atlética, a los cuerpos cuidados, fuertes y musculosos de las mujeres que se identificaban con esta tendencia. Para profundizar, cfr. Castelnuovo et al. (1998) y Gramstad (1999). trasposición de la búsqueda de la igualdad, traspasando las fronteras del género. La pervivencia de estas ideas, vehiculadas por el personaje, influyó, por otra parte, también en las mujeres que lideraron la segunda ola del feminismo, como por ejemplo Gloria Steinem (1934 -), quien creció con el cómic Wonder Woman como referencia. Para este movimiento, que tuvo su máxima expresión en la década de los sesenta, Wonder Woman fue un icono real, admirada por su fuerza, valor y agentividad, que representaba una alternativa al modelo convencional femenino, relegado al espacio doméstico o poco más, con el que habían crecido (Finn, 2014: p. 7) ${ }^{21}$. Sirva como ejemplo el uso de la heroína como icono feminista que hizo Steinem en 1972, cuando la eligió imagen de portada del primer número de MS., la revista feminista creada por ella junto a Dorothy Pitman Hughes. En dicha portada la imagen iba acompañada por el eslogan «Wonder Woman for President» ${ }^{22}$.

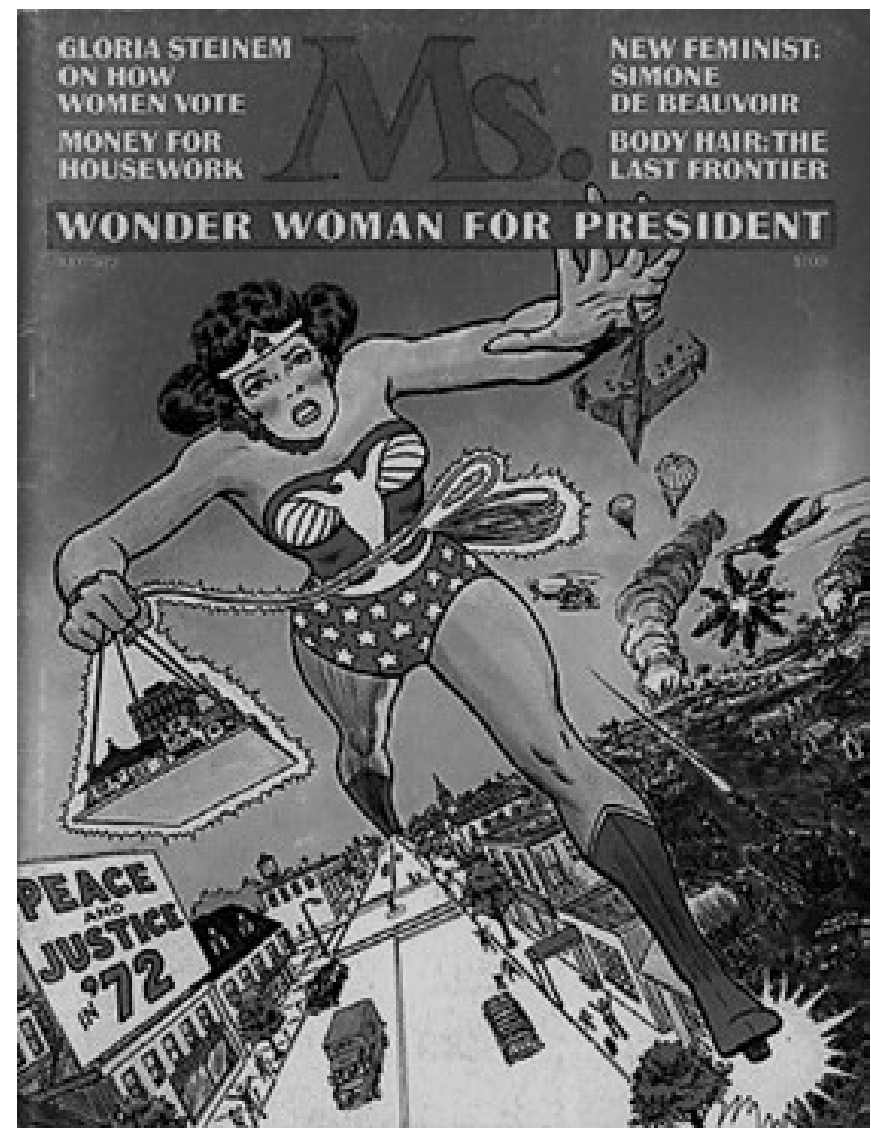

Figura 4. Portada de la revista Ms. - Julio 1972.

\section{La teoría DISC}

No se puede ignorar, por otra parte, que Marston fue, ante todo, un psicólogo. Además de la supuesta invención del detector de mentiras, dio a conocer sus ideas a través de numerosas publicaciones, entre las que destacan The Emotions of Normal People (1928) o Try Living (1937); en ellas presentaba su teoría más famosa, la teoría DISC, acrónimo de

21 Para una reflexión acerca de los elementos característicos de la tercera ola del feminismo y su tratamiento en Wonder Woman a partir de los años ochenta, véase Cocca (2014).

22 La heroína volvió a protagonizar el frontispicio de la revista en 2012, en ocasión de su cuadragésimo aniversario. 
Dominance, 'dominio', Inducement, 'inducción', Submission, 'sumisión', y Compliance, 'conformidad'. Su reflexión tenía como base la consideración de que toda emoción positiva es natural, frente a las negativas, que no lo son. De entre las emociones positivas, los sentimientos amorosos (como la pasión o la fascinación) eran para Marston los únicos que garantizaban la consecución de la felicidad. Por ende, la inducción y la sumisión eran, en su teoría, emociones positiva $^{23}$, ya que facilitaban la sumisión voluntaria de uno al poder de otro individuo.

Como ya he afirmado anteriormente, Wonder Woman fue para Marston un vehículo para presentar sus teorías, no solo las feministas, sino también las psicológicas, a un público más amplio que el académico, a través de la modelación de las emociones que él consideraba superiores (la sumisión y la inducción) en la personalidad de Diana, así como en sus actos físicos y comunicativos. Por esta razón, en muchas ocasiones la tendencia principal de la heroína es la de solucionar los conflictos con sus enemigos a través del diálogo, recurriendo a la fuerza y a la dominación tan solo en situaciones de extrema necesidad.

\section{LESBIANIZANDO WONDER WOMAN}

Más allá de las apropiaciones feministas del mito clásico de las amazonas, mediadas por el cómic Wonder Woman y fomentadas por el mismo uso que de él hizo Marston, otro colectivo escogió a Diana Prince para identificarse, aunque con mucha probabilidad esta identificación no entraba en las intenciones del creador de la historieta. Este cómic nació "para educar» a un público fundamentalmente masculino, «for young boys to identify across gender to a feminine ideal» (Spieldenner, 2012: p. 3), pero fue recibido también por parte de un público lector homosexual, de manera especial por las mujeres lesbianas, quienes desarrollaron su apropiación particular. El cómic original, tal y como fue ideado por Marston, no representaba de manera explícita ningún elemento que se pudiera reconocer como una relación lésbica, aunque sí contenía rasgos que podían facilitar una interpretación en este sentido. Estos elementos pueden describirse de la siguiente manera ${ }^{24}$ :

(1) Contexto homoerótico

Lo que el creador del cómic introdujo en sus viñetas fue, sin lugar a duda, un entorno homoerótico, tanto en Isla Paraíso como entre las Holliday Girls, las hermanas de la sororidad Beeta Lambda, que funciona como contraparte en el Mundo de los Hombres de las amazonas en Temiscira. A todos los efectos, no se trataría de un entorno homoerótico declarado, sino de un espacio creado para hacer confluir en él las más variadas representaciones de las sexualidades de los personajes, reflejo de la opinión sobre el tema de Marston, que incluía prácticas cercanas al bondage.

23 Marston define la sumisión (1928: p. 222) como una manera de estrechar un vínculo entre aliados, en el momento en el que el más débil se somete de manera voluntaria al más fuerte; por otra parte, ejemplifica la inducción (1928: p. 245) a través del movimiento de atracción gravitacional entre un cuerpo más grande y otro más pequeño, por lo que correspondería a una fuerza combinada entre la sumisión voluntaria del elemento más débil de una relación y la atracción del más fuerte.

24 El más reciente acercamiento al tema de la presencia del lesbianismo en Wonder Woman ha sido presentado por Penrose (2019; p. 206-210), al que sigo de cerca, con el añadido de otras reflexiones propias.
(2) La ambigüedad del personaje de Etta Candy

Algunos estudiosos ${ }^{25}$ han querido ver en el nombre del personaje de Etta Candy, líder de la sororidad Beeta Lambda y sidekick ${ }^{26}$ de Diana en el Mundo de los Hombres, un lusus nominis, un juego de palabras, que reside en su pasión por los caramelos (Etta de eat, 'comer', y candy, 'caramelo'). La ambigüedad de este personaje se mostraría de manera evidente en el primer número de la serie (Sensation Comics \#1, 1942); en una de las primeras páginas, una conversación entre Diana y Etta deja margen para una interpretación de doble sentido sexual por el uso del término candy, 'caramelo', que, en el lenguaje coloquial estadounidense, se usa en referencia a los genitales femeninos. Ante la observación de Diana sobre la excesiva cantidad de caramelos que su compañera come y ante la hipótesis de que esa pueda ser la causa por la que Etta no encuentra un hombre, esta última contesta: «Who wants to? When you've got a man, there's nothing you can do with him... but candy you can eat!» (Figura 4). Podemos suponer que este tipo de contenido no fuera evidente para el lector de la época, pero algunos estudiosos (Berlatsky, 2015: p. 152) están convencidos de la interpretación lésbica de la viñeta y usan como justificación el personaje al fondo de la escena, un hombre fuera del foco de atención, que podría ser una representación del mismo Marston y que parece mirar a Etta de manera lasciva, con cierto matiz voyeur, referencia, quizá, a la libertad en las prácticas sexuales del mismo autor con sus compañeras.

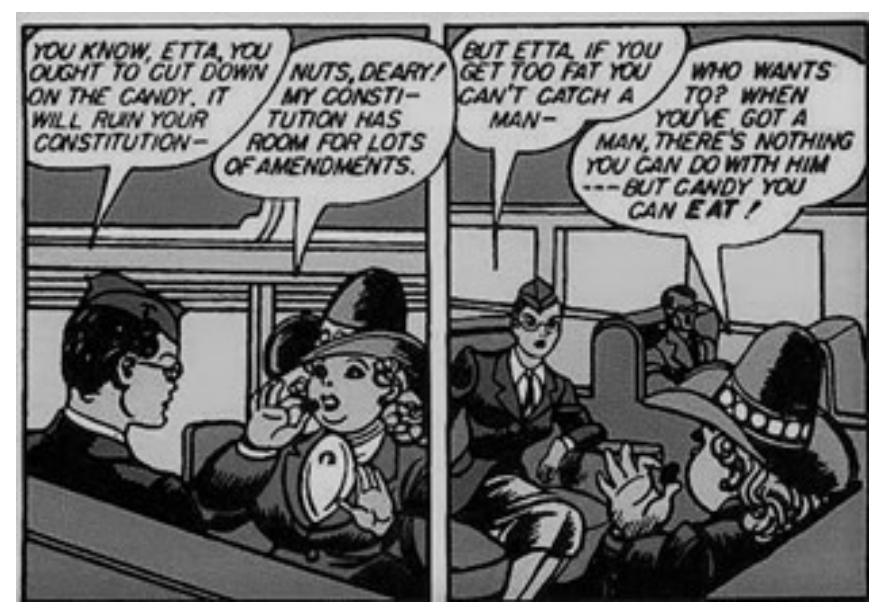

Figura 5. Wonder Woman \#1 - Verano 1942 (TM \& @ 2020 DC COMICS).

(3)La presencia de Safo.

El mismo Marston, en su ensayo The Emotions of Normal People (1928: p. 338), consideraba el homoerotismo femenino como un recurso al que las jóvenes mujeres podían echar mano para prepararse para la relación afectiva y, sobre todo, sexual, con un hombre. Esta consideración se acerca bastante a las teorías más comunes en la época del creador de Wonder Woman sobre Safo (siglo VII-VI a.n.e.), la famosa

25 Pueden consultase, por ejemplo, Young (2018: pp. 228-232), Robinson (2004: p. 41) y Berlatsky (2015: p. 152).

26 Con este término se indica al compañero o compañera del personaje principal de un cómic, serie, película o novela. Suele ser más joven que el principal y da pie, en ocasiones, a la introducción de matices homosexuales en su relación. Entre los ejemplos más conocidos se recuerdan Robin, sidekick de Batman en el homónimo cómic, o Gabrielle, sidekick de Xena en la serie Xena: Warrior Princess. 
poetisa griega procedente de la isla de Lesbos, cuyos poemas estaban dedicados a jóvenes mujeres que frecuentaban

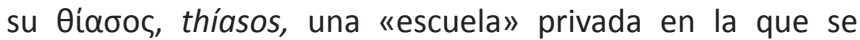
preparaban para el matrimonio, mediante el aprendizaje de la música, la danza y la poesía, mientras se formaban en el arte de amar. No es una mera coincidencia, pues, que Safo sea una de las más frecuentes presencias lésbicas en el cómic, ni que una de las expresiones más utilizadas por la heroína sea "Suffering Sappho!», 'iSufriente Safo!' (Figura 6). Esa insistencia en el referente de la poetisa griega podría justificarse por la influencia de Elizabeth Holloway y su ya señalada pasión por los versos de Safo en la labor de creación del personaje.

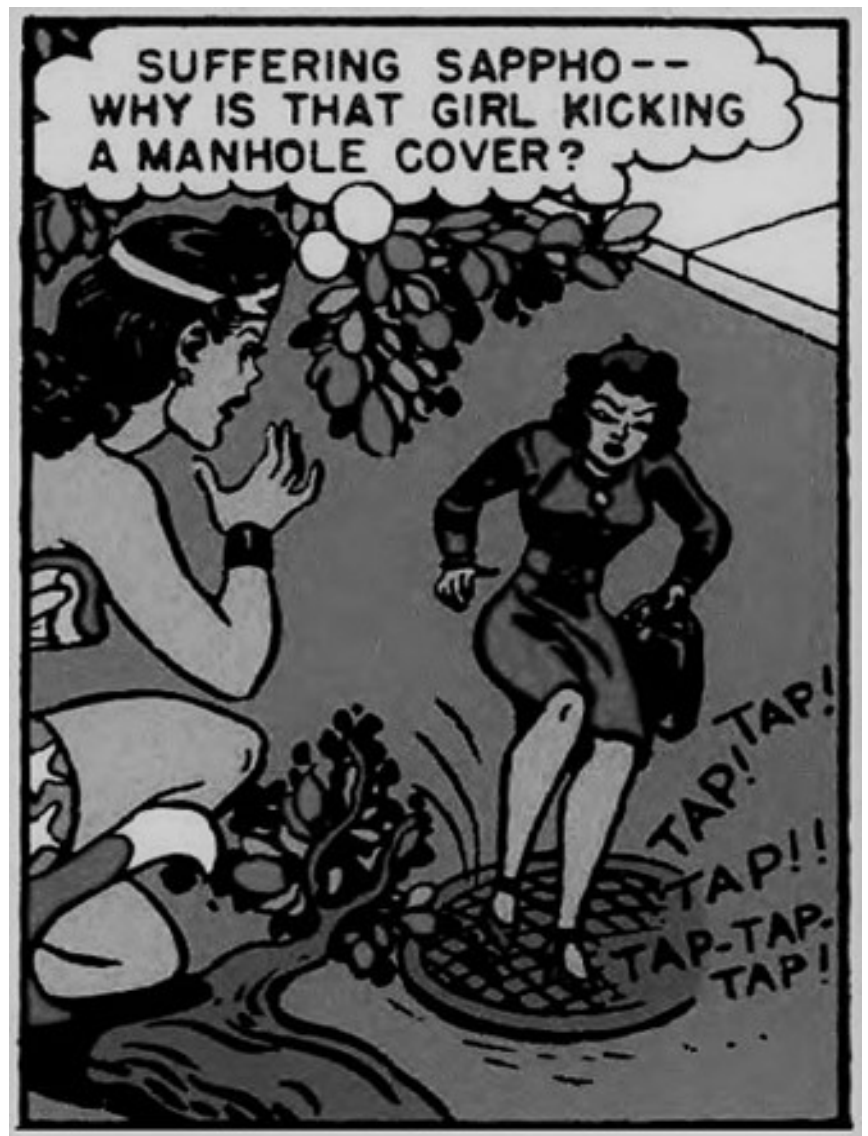

Figura 6. Wonder Woman \#28 - Marzo 1948 (TM \& (C) 2020 DC COMICS).

La alusión al referente sáfico podría parecer poco relevante hoy en día, pero sin duda lo fue en las décadas de los cuarenta y los cincuenta, los primeros años de publicación del cómic. Hasta tal punto incidió en la percepción lésbica del personaje de Wonder Woman que se convirtió en uno de los objetivos de la crítica del doctor Frederic Wertham (1895 1981). Este psiquiatra germano-estadounidense publicó en 1954 un libro titulado Seduction of the Innocent, en el que exponía su lucha contra la mala influencia de los medios de masas, sobre todo del cómic, en el desarrollo infantil y de la adolescencia. En el caso de Wonder Woman, Wertham argumentó que el cómic fomentaba el lesbianismo, así como, en el caso de Batman, su relación con su sidekick Robin favorecía, en la historieta homónima, la homosexualidad masculina, colindante con la pederastia ${ }^{27}$.

27 Para más detalles, véase This (2014) y Lepore (2014: p. 170-171).
El resultado de la presión social que suscitaron estas consideraciones, junto con una serie de audiencias del Senado estadounidense sobre el tema, llevaron al nacimiento de la Comic Code Authority, un organismo creado por los mismos editores de historietas para regular (mejor dicho, autocensurar) los contenidos de las obras, con el fin de evitar la censura estatal o posibles procedimientos penales en su contra. El reflejo más evidente para Wonder Woman, como ya se adelantaba al principio, fue la introducción de un elemento romántico muy marcado; a partir de este momento, las preocupaciones de la heroína se fueron orientando hacia la búsqueda del amor de un hombre, que culminó en el conocido romance con Steve Trevor, piloto y espía de la Aviación estadounidense ${ }^{28}$.

(4)Las amazonas y el espacio

Otro elemento lésbico, en el que he venido insistiendo en este trabajo, radica en que Diana sea una amazona, una mujer guerrera que cruza las fronteras de los roles de género establecidos. Las amazonas habían sido consideradas un modelo de referencia por las propias feministas ya desde el origen del movimiento, en el tiempo de las sufragistas que recibían el apelativo de "amazonas». Tras un amplio salto temporal, en los años setenta, momento álgido de la segunda ola del feminismo, la sexualidad entró de pleno en la agenda del movimiento y la sección lésbica del frente feminista propuso una nueva interpretación del mito clásico: las amazonas se convirtieron en un modelo, no simplemente por su fuerza, autonomía y agentividad, sino también porque vivían separadas del género masculino ${ }^{29}$. De acuerdo con esta premisa, un grupo de feministas, coincidiendo con el nacimiento del movimiento de liberación homosexual, incluyó en los objetivos de su resistencia una vida lejos de los hombres, puesto que consideraban esta estrategia como la única posibilidad para las mujeres de reaccionar frente al patriarcado. Esto, por supuesto, iba a ser más fácil de llevar a cabo y más práctico para las mujeres lesbianas. Por lo tanto, es posible conjeturar que las mujeres portadoras de estos nuevos ideales radicales crecieron leyendo Wonder Woman y que Isla Paraíso fue para ellas la representación de este espacio perfecto en el que llevar a cabo su utopía, puesto que en esta tierra las parejas del mismo sexo eran la única solución posible (Spieldenner 2012: p. 5).

La isla, por lo tanto, representa una vez más la separación de la realidad hegemónica, el único espacio en el que la otredad puede llegar a concretarse ${ }^{30}$. El hecho de

28 Algunos estudiosos (Penrose, 2014: p. 195) leen también en la relación entre Diana Prince y Steve Trevor un guiño al mundo clásico, de manera específica al mito de Antíope, la amazona raptada por Teseo. En el caso del cómic, el personaje que en repetidas ocasiones necesita ser rescatado de una situación de peligro es Steve Trevor, que actúa como damisela en apuros; Diana se enamorará de él y decidirá seguirlo, de manera espontánea. Con respecto al mito clásico se produce aquí una clara inversión en la representación de los roles de género, evidente sobre todo en la agentividad del personaje femenino, subrayada por la decisión personal de Diana de renunciar a su isla, una vez más relacionada con la sumisión positiva de la que hablaba Marston en su teoría DISC.

29 En estos años se fecha el nacimiento del movimiento lesbofeminista en Estados Unidos, que considera el lesbianismo como el resultado lógico del feminismo y rechaza la heterosexualidad en cuanto institución social. Para más detalle, véanse Rich (1986) y Jeffreys (2003), ambas activistas y teóricas del movimiento lesbofeminista.

30 Sobre la relación existente entre la mujer y la isla, por ejemplo, en las representaciones femeninas de la Odisea homérica, véase Deriu (2019). 
que Isla Paraíso esté rodeada por el mar y, además, oculta al resto del mundo, la convierte en el espacio ideal para que todo aquello considerado no normativo por la ideología dominante encuentre su expresión. Se trata de un elemento ya presente en el arquetipo clásico, puesto que, a pesar de una falta de acuerdo entre los autores grecorromanos sobre la exacta ubicación geográfica de las amazonas, todos coinciden en localizarlas lejos de la civilización. En ocasiones, el recurso a la lejanía espacial puede ser reforzado por la lejanía temporal, presente de alguna manera también en el relato mitológico amazónico y en su transposición en el cómic de Marston: si, por un lado, las fuentes clásicas hacen referencia a los acontecimientos relacionados con el pueblo de las mujeres guerreras como algo ocurrido en tiempos de héroes como Aquiles, Heracles o Teseo, es decir, el tiempo del mito, por el otro, el cómic transporta la sociedad amazónica al mundo real y contemporáneo al autor, pero justificando su existencia mediante una separación de algún modo divina, que la mantiene oculta del resto del mundo. La isla se ha convertido en un no-lugar atemporal y ucrónico, imagen del pasado arcaico en la contemporaneidad, una utopía abocada al fracaso ya en los términos de su formulación, en su lucha contra los ideales hegemónicos del tiempo.

Asimismo, Isla Paraíso constituye la imagen de un sistema cerrado y seguro. Ya desde sus orígenes, la historieta, además de la atención del público masculino y del público feminista, atrajo a otro no previsto por Marston, unos seguidores queer, fenómeno que se intensificó a lo largo de los años setenta. En esta década, el cómic cruzó las fronteras de los medios artísticos y aterrizó en televisión con la serie Wonder Woman, con Lynda Carter en el papel protagonista de Diana. El paso de un medio a otro iba acompañado por una nueva estética, de corte $c a m p^{31}$ : la exageración y la ostentosidad de las situaciones que esta estética favorecía encajaban bien con la contracultura que, a partir de 1969, tras los disturbios de Stonewall, había ido caracterizando a la cultura homosexual de la época, por lo que se había ido estableciendo un fuerte vínculo entre el camp y la representación de este colectivo marginal. Lo que está claro es que la nueva representación camp de Wonder Woman, así como su apropiación feminista, constituyeron las bases para el aumento del número de seguidores queer del cómic de DC a lo largo de la década de los setenta, coincidiendo con un fenómeno definido por algunos estudiosos como «migración homosexual» (Hood, 1998). Es justo en estos años cuando empiezan a surgir en Estados Unidos comunidades homosexuales y se va consolidando la idea según la cual las grandes ciudades podían adaptarse mejor y ser más acogedoras para las identidades no normativas, a diferencia de los pequeños núcleos urbanos. En este contexto se desarrollaron barrios como el de Castro en San Francisco o The Village en Nueva York, sistemas cerrados y espacios seguros para la expresión del deseo sexual no normativo. En ello quizá podría haber cierta influencia del modelo de Temiscira.

A estas consideraciones acerca del espacio para la expresión identitaria habría que sumar otro elemento más que relaciona el mundo LGBTQI+ con Wonder Woman. Me

31 Aportes teóricos fundamentales sobre el camp son las reflexiones de Sontag (1964) y Meyer (1994) refiero a la búsqueda de un lugar en el mundo. Así como las identidades en general (y las no normativas de manera más evidente), también Diana Prince, más allá de las numerosas aventuras vividas, necesita ubicar su identidad, emocional y físicamente. El sentido de pertenencia a una realidad y un espacio compartidos, ya sea en Isla Paraíso con otras amazonas, o bien en un contexto social y urbano no discriminatorio, pudo contribuir a fortalecer la seguridad de estos individuos en su proceso de definición de su propia identidad.

(5) Doble vida y máscaras

Más allá de las alusiones directas o indirectas al lesbianismo y a contextos identitarios no normativos, es importante subrayar las oportunidades que un cómic como Wonder Woman ofrece, sobre todo a la hora de proporcionar elementos cargados de ambigüedad que puedan estar sujetos a interpretaciones dispares ${ }^{32}$. Todos los superhéroes -y Wonder Woman no es una excepción- presentan dos elementos clave que las favorecen. La primera es la doble vida del personaje principal que, además de su identidad como héroe o heroína, vive una vida civil, cotidiana, en la que a menudo es un individuo marginado. Entre los varios oficios que desempeña Diana Prince en el Mundo de los Hombres, por ejemplo, trabaja como secretaria de Steve Trevor o como dependiente de una tienda de ropa en los años sesenta y setenta, cuando renunció a sus poderes para permanecer al lado de Trevor. El segundo factor propio del personaje superheroico del cómic es el uniforme que, junto con la máscara, permite ocultar su identidad; se trata de una decisión que puede deberse tanto al miedo a perder la credibilidad y el apoyo del público ante el descubrimiento de su identidad civil como, simplemente, al temor a ser heridos, emocional y físicamente, una vez desvelado su yo. Diana recurre al uniforme que he descrito al principio de este trabajo, que le permite aprovechar sus poderes (fuerza, agilidad y, por supuesto, seducción, un arma típicamente femenina), al mismo tiempo que vehicula una exaltación ideológica del poder político estadounidense. No cubre su rostro con una máscara propiamente dicha, sino que, a la manera de Clark Kent/Superman, en su identidad civil recurre a unas gafas que impiden que pueda ser reconocida por el mismo Steve Trevor.

Se trata, por tanto, de elementos que no implican de por sí la existencia de una identidad no normativa detrás del héroe o heroína, pero la ambigüedad que conllevan propicia una lectura queer como la que hicieron en la década de los años setenta los colectivos homosexuales (Spieldenner, 2012: p. 7-8). Como ya se ha indicado anteriormente, este proceso no se da solo en el público lésbico de la historieta, sino que se extiende también a todos aquellos lectores que se identifican con el personaje, a través de la asociación de la doble vida y la máscara con su propia experiencia de vida «dentro del armario».

\section{Una propuesta de análisis}

En palabras de Meredith Safran y Monica Cyrino en su introducción al volumen Classical Myth on Screen (2015: p. 1),

32 Sobre el formato cómic como lugar de expresión de identidades queer femeninas, véase Abate et al. (2018). 
«the narratives, characters and symbols, found in canonical texts $^{33}$, take on new dimensions as they are repeatedly absorbed and filtered through subsequent historical-cultural sensibilities, in media ranging from comic books to television shows to video games». El arquetipo clásico de la mujer guerrera ha experimentado este proceso a lo largo de los siglos y el cómic Wonder Woman ha sido solo una de las muchas formas de apropiación que ha vivido en el tiempo.

Es posible entender esta dinámica a través de la teoría de la Recepción Clásica desarrollada por Lorna Hardwick (2003: p. 5), quien sugirió que en los procesos de recepción de un referente clásico intervienen múltiples variantes, que podemos intentar aplicar al cómic Wonder Woman y su recepción por parte del colectivo lésbico. Además del objeto de interés (el arquetipo de la amazona) y la coordenada espaciotemporal en la que se produce, con especial énfasis en los Estados Unidos de la década de los setenta, hay que tener en consideración los agentes de la recepción, el colectivo homosexual, y, de manera específica, el colectivo lésbico. El análisis debe luego centrarse en la manera en la que se ha producido la recepción, que en el caso de Wonder Woman ha sido a través de la eliminación de algunos elementos conflictivos, como el amor romántico hacia un hombre, y la introducción de nuevos matices de significado, como las interpretaciones lésbicas o, en general, no hegemónicas y no normativas del entorno en el que se desarrolla la acción. Por último, el análisis del proceso debe atender también a las finalidades para las que se ha desarrollado esa interpretación concreta: en el caso de las amazonas y su apropiación por parte del colectivo lésbico, encapsulada en el personaje de Wonder Woman, la dinámica se justifica como una estrategia de creación o fortalecimiento de una identidad moderna, lésbica, que encuentra en el arquetipo (la amazona) y en su recepción mediada (Wonder Woman) un modelo autorizado $y$, consecuentemente, legitimador ${ }^{34}$. Resultado de este análisis será, por lo tanto, la observación de la estrecha vinculación entre un fenómeno social y otro cultural, es decir, el reconocimiento de un proceso de construcción de una identidad a través de un referente mitológico y su recepción.

\section{CONCLUSIONES}

En el caso del cómic Wonder Woman encontramos un ejemplo de apropiación, a través de un producto de cultura pop, de un referente clásico, las amazonas, que se enriquece con nuevos significados y valores generados por el Zeitgeist, el espíritu del tiempo en el que fue creado.

Dos procesos se deducen de las consideraciones que he presentado. El primero de ellos es el recurso al mismo personaje con dos finalidades diferentes. En la Antigüedad clásica las amazonas permitieron el fortalecimiento y la justificación del poder masculino, en una sociedad exclusivamente patriarcal, así como la legitimación del conflicto contra lo otro, la barbarie, la incivilizada sociedad amazónica. La tradición primó esta representación de

$33 \mathrm{Y}$, se podrían añadir también, en las imágenes.

34 El caso de Wonder Woman no representa un unicum en el recurso al mundo clásico como referente legitimador de una identidad lésbica moderna. Otro ejemplo, de naturaleza diferente, es la novela gráfica Fun Home. A Family Tragicomic (2006), de Alison Bechdel; léase, al respecto, López Gregoris (2020). la feminidad de las amazonas, destinadas a morir o a la sumisión romántica frente al héroe. Sin embargo, en la década de los cuarenta del siglo XX William Moulton Marston revivificó este arquetipo con el propósito opuesto: gracias a los nuevos matices de significado que la amazona había ido recibiendo por parte de los primeros movimientos en favor de los derechos de la mujer, creó un personaje y un mundo inspirados en la sociedad amazónica del mito, como síntesis de su manera feminista de ver el mundo.

Un proceso más se suma al anterior y la reescritura de Marston se convierte en un nuevo eslabón de la cadena de recepción del referente clásico ${ }^{35}$, que facilitará su apropiación por parte del movimiento feminista y los colectivos homosexuales, mediada por Wonder Woman. Los rasgos característicos del personaje y su entorno, a los que ya Marston había dotado de un matiz de significado claramente orientado a su interpretación feminista, se enriquecen con una nueva simbología, generada por un grupo social marginal. En mi opinión, en Wonder Woman el factor que favorece dichas lectura y apropiación no reside tanto en la representación explícita de la amazona y su sociedad, cuanto en las ambigüedades inherentes al referente original, el arquetipo clásico, y, especialmente, en su sexualidad no-normativa. Aunque en las fuentes clásicas no se haga ninguna mención explícita a ello (ni cabría esperarlo), hay un argumento ex silentio en su descripción: el rechazo de las amazonas a las relaciones afectivas y sexuales con los hombres (con excepción del sacrificio ritual anual para perpetuar su sociedad), primer paso para su lesbianización. El desarrollo posterior del mito llegó casi a eclipsar este hecho, por su incidencia en la sumisión romántica de la guerrera hacia el héroe, pero Marston lo reintrodujo, gracias a la incorporación de elementos ambiguos, como el entorno homoerótico, algunos juegos de palabras (Etta Candy), la doble identidad, el disfraz y, en suma, la elección del referente de la mujer guerrera y luchadora.

Cabe hacer una última reflexión: ¿por qué Wonder Woman y no otro personaje? Como he dicho, no hay referencia explícita al lesbianismo del personaje principal, Diana, ni de otros secundarios, por razones que Kelli Stanley (2005: p. 164-165) justifica de la siguiente manera: «a real lesbian content would push her too far outside the circle of social normality and render her too dangerous. It would also destroy her value as consumer merchandise, created by and for (straight) male consumption $»^{36}$.

El proceso de lesbianización de Wonder Woman, de tal modo, podría, en mi opinión, estar relacionado con la peligrosa cercanía entre las categorías de género, roles de género, sexualidad y orientación. Ha sido, y sigue siendo, una dinámica bastante común a lo largo de las últimas décadas el

\footnotetext{
35 Una reflexión metodológica sobre el diálogo entre lo contemporáneo y lo clásico en los productos de cultura popular puede leerse en Unceta Gómez (2019), quien ejemplifica tres modelos, entre otros, de apropiación contemporánea de la Antigüedad: las recepciones mediadas, la recepción inversa (o influjo recíproco, de diálogo entre lo antiguo y lo moderno) y la recepción como representación del original. El cómic Wonder Woman respondería a una amalgama entre el primero y el segundo modelo (cfr. supra).

36 El personaje de Rey en la saga Star Wars ejemplifica bien la reflexión de Stanley: a pesar de la importancia de su papel en las últimas entregas de la saga, destaca la ausencia de merchandising a ella asociado, quizá debido también a su ambigüedad afectiva y sexual.
} 
considerarlas como sinónimos, por lo que la confusión podría haber generado mecanismos específicos de identificación, como en este caso. El hecho de que Diana, una moderna amazona, domine ámbitos como la guerra y la justicia, la acerca a unos roles de género propiamente masculinos $y$, por ende, a la sexualidad de este género, que, en términos normativos binarios, se proyecta en una atracción hacia el género femenino. Se trata, pues, del proceso según el cual el varón heterosexual medio considera que una mujer «se hace» lesbiana, cuando ocupa el espacio masculino.

Diana de Temiscira, además, no es el único personaje que experimenta esta dinámica interpretativa, pues resulta bastante común entre las mujeres guerreras de la ficción, todas influidas por el antecedente de Wonder Woman, como, por ejemplo, Xena, de Xena: Warrior Princess (NBC, 1995-2001), Mulan de la homónima película Disney (Barry Cook y Tony Bancroft, 1998), Katniss Everdeen en The Hunger Games (Gary Ross, 2012, versión cinematográfica de la homónima novela de Suzanne Collins, de 2008), Arya Stark de la serie Game of Thrones (HBO, 2011-2019), la princesa Mérida en Brave (Mark Andrews y Brenda Chapman, 2012), y muchas más. Todas ellas, además, comparten una iconografía específica, notablemente sexualizada (menos en el caso de las películas Disney, prioritariamente dirigidas a un público infantil), así como el uso de armas como arcos, flechas, lazos, etc., que subrayan la distancia física, cuando no emocional, de su objetivo y las relacionan con la diosa griega de la caza Ártemis (Diana en el mundo romano), a cuyo culto eran devotas las amazonas.

Todas estas heroínas representan a la vez un ejemplo de recepción del arquetipo clásico de la mujer guerrera, la amazona, pero también ilustran dos interesantes procesos de transferencia cultural por los que se interesa la teoría de la Recepción Clásica: por una parte, la manera en la que dicho arquetipo ha sido remodelado por parte de creadores de productos artísticos y, por otra, el modo en que ciertos colectivos convertidos en los receptores finales de esos productos se han apropiado del referente (gracias a sus ambigüedades) para sus propios fines. Me refiero, claro está, a las mujeres lesbianas, quienes se han servido de Wonder Woman como un referente para crear su identidad y para encontrar su lugar en el mundo.

\section{AGRADECIMIENTOS}

Este trabajo ha sido elaborado gracias a un contrato de investigación predoctoral FPI-UAM 2019, en calidad de miembro del equipo de investigación "Marginalia Classica: Recepción Clásica y cultura de masas contemporánea. La construcción de identidades y alteridades" (Ref. PID2019107253GB-100) y del grupo de investigación de la Universidad Autónoma de Madrid «LITTERAE: Literatura, comparatismo y recepción desde la Antigüedad hasta hoy». Mis agradecimientos van a los revisores anónimos del trabajo por sus acertadas sugerencias.

\section{REFERENCIAS}

Abate, Michelle Ann, Grice, Karly Marie y Stamper, Christine N. 2018. Introduction: 'Suffering Sappho!': Lesbian Content and Queer Female Characters in Comics. Journal of Lesbian Studies 22(4): 329-335.

Berlatsky, Noah. 2015. Wonder Woman: Bondage and Feminism in the Marston/Peter Comics, 1941-1948. New Brunswick/New Jersey/London: Rutgers University Press.

Call, Lewis. 2013. BDSM in American Science Fiction and Fantasy. New York/Hampshire: Palgrave Macmillan.

Castelnuovo, Shirley y Guthrie, Sharon R. 1998. Feminism \& the Female Body: Liberating the Amazon Within. Boulder: Lynne Rienner Publishers.

Cyrino, Monica y Safran, Meredith E. (eds.). 2015. Classical Myth on Screen. New York: Palgrave and Macmillan.

Cocca, Carolyn. (2014) Negotiating the Third Wave of Feminism in Wonder Woman. PS: Political Science \& Politics 47.1: 98-103.

Davies, Peter. 2009. Women Warriors, Feminism and National Socialism: The Reception of J. J. Bachofen's View of Amazons among German and Austrian Right-Wing Women Writers. En Women and Death 2, Sarah Colvin y Helen Watanabe-O'Kelly (Eds.), 45-58. Rochester/New York: Camden House.

Deriu, Morena. 2019. Not Every Woman is an Island: Some Notes about Isles of Women and Colonisation in the Odyssey. Rhesis. International Journal of Linguistics, Philology, and Literature 10(2): 19-32.

Dowden, Ken. 1997. The Amazons: Development and Functions. Rheinisches Museum 140(2): 97-128.

Duncan, Randy y Smith, Matthew J. 2009. The Power of Comics. History, Form and Culture. New York/London: Bloomsbury.

Fabre-Serris, Jaqueline. 2019. Ripensare il genere. Alcune riflessioni sulle riscritture del mito delle Amazzoni. Conferencia presentada en el congreso "Crossing Gender Boundaries. Brave Women Living in Texts and Images", 26-28 de noviembre, Santa María Capua Vetere.

Finn, Michelle R. 2014. William Marston's Feminist Agenda. En The Ages of Wonder Woman. Essays on the Amazon Princess in Changing Times, Joseph J. Darowski (ed.), 7-21. Jefferson/London: McFarland \& Company, Inc., Publishers.

Gramstad, Thomas. 1999. The Female Hero. A RandianFeminist Synthesis. En Feminist Interpretations of Ayn Rand, Mimi Reisel Gladstein y Chris Matthew Sciabarra (eds.), 333-362. Pennsylvania State University Press.

Hardwick, Lorna. 2003. Reception Studies. Oxford: Oxford University Press.

Hatfield, Charles. 2005. Alternative Comics: an Emerging Literature. Jackson: University Press of Mississippi.

Hood, Clifton. 1998. Gay New York: Gender, Urban Culture, and the Making of the Gay Male World, 1890-1940. Journal of Urban History 24(6): 782-793.

Jeffrey, Sheila. 2003. Unpacking Queer Politics: A Lesbian Feminist Perspective. Cambridge: Polity.

Kovacs, George y Marshall, Christopher W. (Eds.). 2011. Classics and Comics. New York: Oxford University Press.

Kovacs, George y Marshall, Christopher W. (Eds.). 2015. Son of Classics and Comics. New York: Oxford University Press.

Lepore, Jill. 2014. The Secret History of Wonder Woman. New York: Alfred A. Knopf.

López Gregoris, Rosario. 2020. Fun Home: A Family Tragicomic. Homer, Joyce and Bechel. Classical Reception and Comic Hybridization. The Heroine Explores Her Sexual Identity. En 
The Hero Reloaded. The Reinvention of the Classical Hero in Contemporary Mass Media, Rosario López Gregoris y Cristóbal Macías Villalobos (Eds.), 143-157. Amsterdam/ Philadelphia: John Benjamins Publishing Company.

Masotta, Oscar. 1970. La historieta en el mundo moderno. Barcelona: Ediciones Paidós.

Mayor, Adrienne. 2014. Amazonas. Guerreras del mundo antiguo. Traducción de Jorge García Cardiel. Madrid: Desperta Ferro Ediciones.

Marston, William Moulton. 1928. The Emotions of Normal People. London/New York: Kegan Paul/Harcourt.

McCausland, Elisa. 2017. Wonder Woman. El feminismo como superpoder. Madrid: Errata Naturae.

Meyer, Moe. 1994. The Politics and Poetics of Camp. London: Routledge.

Penrose, Walter D. Jr. 2019. The Unwanted Gaze? Feminism and the Reception of the Amazons in Wonder Woman. EuGeStA 9: 176-224.

Perrotta, Annalisa. 2015. La sfida di Rovenza dal martello, donna, guerriera e regina: analisi di un episodio della saga di Rinaldo da Montalbano, Rassegna Europea di Letteratura Italiana 45/46: 39-59.

Rich, Adrienne. (1986). Compulsory Heterosexuality and Lesbian Existence (1980). En Blood, Bread, and Poetry: Selected Prose 1979-1985, Adrienne Rich, 23-75. New York/London: W.W. Norton \& Company.

Robinson, Lillian. 2004. Wonder Women: Feminisms and Superheroes. London: Routledge.

Sánchez Pérez, Carlos. 2019. Hermes Trismegisto: de la mística a la fantasía. Pervivencia de los textos herméticos de la antigüedad a nuestros días. Tesis doctoral, Universidad Autónoma de Madrid.

Santini, Daria. 2009. The German Reception of the Amazon Myths from Hederich to Bachofen. En Women and Death 2, Sarah Colvin y Helen Watanabe-O'Kelly (Eds.), 15-27. Rochester/New York: Camden House.

Sontag, Susan. 1964. Notes on "Camp". Penguin Books.

Spieldenner, Andrew R. 2012. Altered Egos: Gay Men Reading across Gender Difference in Wonder Woman. Journal of Graphic Novels and Comics, 1-10.

Stanley, Kelli E. 2005. 'Suffering Sappho!': Wonder Woman and the (Re)Invention of the Feminine Ideal. Helios 32(2): 143-171.

This, Craig. 2014. Containing Wonder Woman: Fredric Wertham's Battle Against the Mighty Amazon. En The Ages of Wonder Woman. Essays on the Amazon Princess in Changing Times, Joseph J. Darowski (ed.), 30-41. Jefferson/London: McFarland \& Company, Inc., Publishers.

Unceta Gómez, Luis. 2019. El epítome como representación del original. Algunos ejemplos del diálogo posmoderno con la antigua Roma. En En los márgenes de Roma. La Antigüedad romana en la cultura de masas contemporánea, Luis Unceta Gómez y Carlos Sánchez Pérez (eds.), 17-35. Madrid: UAM-Los libros de la Catarata.

Unceta Gómez, Luis. 2020. From Hero to Superhero. The Update of an Archetype. En The Hero Reloaded. The Reinvention of the Classical Hero in Contemporary Mass Media, Rosario López Gregoris y Cristobal Macías Villalobos (eds.), 1-17. Amsterdam/Philadelphia: John Benjamins Publishing Company.
United Nations. 2016. Wonder Woman Appointed UN Honorary Ambassador for the Empowerment of Women and Girls. UN News, 21 de octubre. Consultado el 10/03/2020. https://news.un.org/en/ story/2016/10/543462-wonder-woman-appointed-unhonorary-ambassador-empowerment-women-and-girls.

Young, Serinity. 2018. Women Who Fly: Goddesses, Witches, Mystics, and other Airborne Females. New York: Oxford University Press.

Wittig, Monique. 1992. El pensamiento heterosexual y otros ensayos. Traducción de Javier Sáez y Paco Vidarte. Barcelona, Madrid: Egales. 